\title{
Conservative enteral feeding policy and necrotizing enterocolitis (NEC) in VLBW infants: a single center experience
}

\begin{abstract}
Background: One of the major modifiable risk factor for necrotizing enterocolitis (NEC) in very low birth weight (VLBW) infants is related to enteral feeding practices.

Objective: The primary outcome was to determine a potential association of slow rates of enteral feed advancement and the incidence of NEC in VLBW infants.

Method: Single center retrospective analysis at a tertiary University Children's Hospital over a 2-year study period (01/2009 and 12/2010)

Results: A total of 103 VLBW (mean birth weight 1121 266 grams; range: 570-1490; 10 $25^{\text {th }}$ percentile) were included. Mean duration until first feeds were started was $2.2 \pm 1.0$ days (range: 1-7 days). Median time until full enteral feeds were achieved was 20 days (range: $10-48)$ days with a mean weight of $1313 \pm 311$ grams $\left(3-10^{\text {th }}\right.$ percentile; range: $620-2000$ grams). Neonates were discharged/transferred after 63.0 26.6 days (range: $12-141)$ with a mean weight of $2647 \pm 450$ grams $\left(<3^{\text {rd }}\right.$ percentile; range $1030-3630$ grams $)$. The incidence of NEC (Bell's stage $\geq 2 a$ ) was $0 / 103(0 \%)$. In 5/103 neonates, catheter-related bloodstream infections (2.4 infections/1000 device days) occurred.
\end{abstract}

Conclusion: Slow advancement of enteral feeds in VLBW infants was associated with a dramatically low rate of NEC without unduly increasing the number of catheter-related infections. Large randomized controlled trials (RCTs) are necessary that will compare both short and long term outcome variables after conservative vs. aggressive enteral feeding regimes in this susceptible cohort.

Keywords: necrotizing enterocolitis, very low birth weight infants, enteral feeding regimen
Volume I Issue I - 2014

\author{
Mona Butte,' Ulrike Lindner, ${ }^{2}$ Harald Sauer, ${ }^{2}$ \\ Dominik Schondorf, ${ }^{3}$ Ludwig Gortner, ${ }^{1,2}$ \\ Sven Gottschling,' Kristina Dahmen,' Sascha \\ Meyer ${ }^{1,2}$ \\ 'Medical School, University Hospital of Saarland, Germany \\ ${ }^{2}$ Department of Pediatrics and Neonatology, University \\ Children?s Hospital of Saarland, Germany \\ ${ }^{3}$ Section Pediatric Gastroenterology, Hepatology and Nutrition, \\ University Children?s Hospital of Saarland, Germany
}

Correspondence: Sascha Meyer, Department of Pediatrics and Neonatology, University Hospital of Saarland, Building 9, 6642 I Homburg, Germany, Tel 490-684 I- 16283 I3, Fax 490-684 |1628452,Email sascha.meyer@uniklinikum-saarland.de

Received: April 17, 2014 | Published: May 05, 2014
Abbreviations: BPD, bronchopulmonary dysplasia; CRBSI, catheter-related bloodstream infections; FIP, focal intestinal perforation; IVH, intraventricular haemorrhage; NEC, necrotizing enterocolitis; ROP, retinopathy of prematurity; SGA, small for gestational age; VLBW, very low birth weight infants

\section{Introduction}

Necrotizing enterocolitis (NEC) is the most important acquired intestinal complication during the neonatal period with very low (VLBW) and extremely low birth weight (ELBW) preterm infants at greatest risk. ${ }^{1}$. Data from large, multicenter, neonatal network databases from the United States, Canada and Germany report a mean prevalence of around $4-7 \%$ in infants weighing $<1500 \mathrm{~g}$ and an estimated mortality of $15 \%-30 \%$, depending on the gestational age of the infant. ${ }^{2-5}$

Necrotizing enterocolitis has also been one of the most difficult disorders to eradicate and its pathogenesis, for example occurrence of infectious-like outbreaks, remains as elusive as optimal strategies for prevention and treatment, despite decades of research. ${ }^{1}$ While data from RCTs and meta-analyses indicate that some factors may positively influence the incidence of NEC (e.g. use of antenatal steroids, breast milk, probiotics), ${ }^{6,7}$ there is an ongoing controversy with regard to enteral feeding practices and regimens. ${ }^{8-13}$ The most recent guideline published by the American Society of Parenteral and Enteral Nutrition (A.S.P.E.N) suggests increasing enteral feeds by 30 $\mathrm{ml} / \mathrm{kg} /$ day although the evidence for this approach is weak. ${ }^{14}$. Surveys including large numbers of neonatal intensive care units (NICUs) in the United States indicate that most neonatologists tend to increase daily enteral feeds by substantially smaller amounts $(10-20 \mathrm{ml} / \mathrm{kg} /$ day), ${ }^{15}$ although feeding strategies may vary substantially between countries and institutions. ${ }^{16}$

Possible benefits of accelerated enteral feeding include shorter period of parenteral nutrition, improved early postnatal growth with an earlier regain of birth weight, a lower rate of catheter-related infections, a shorter hospital stay, and reduced cost of neonatal careassuming such practice is not associated with increased morbidity (i.e. including need for surgery and survival with short bowel syndrome and its consequences such as recurrent sepsis and dependence on total parenteral nutrition). The occurrence of severe NEC (Bell's stage $\geq 2$ a) has been strongly associated with long-term morbidity, including severe neurological impairment. ${ }^{17}$. Conversely, the use of growth as the sole or principal outcome measure to assess preterm nutrition is flawed as we still do not know exactly what represents optimal growth. ${ }^{18}$

Given the contradictory data published in the current literature with regard to the incidence of NEC and its potential association with aggressive enteral feeding regimens in VLBW infants, ${ }^{19}$ the aim of this study was to assess our own feeding policy (conservative regimen with daily increases in enteral feeds of $5-10-15 \mathrm{ml} / \mathrm{kg}$ ) and relate it to the incidence of NEC in our NICU. Primary outcome measure was the incidence of NEC. Furthermore, daily increase in feeding volumes, time to full feeds, growth patterns (body weight/length and head 
circumference), and catheter-related blood stream infections while being treated in our hospital were recorded.

\section{Patients and methods}

This retrospective cohort analysis was performed at the University Children's Hospital of Saarland, Homburg, Germany. Institutional Review Board approval was obtained prior to the study from the Institutional Review Board and Ethics Committee of the University Hospital of Saarland, Saarbrücken, Germany.

\section{Study population and data collection}

We evaluated all inborn infants with a birth weight $<1500 \mathrm{~g}$, born between January 1, 2009 and December 31, 2010. Exclusion criteria were congenital malformations of the gastrointestinal tract, death or transfer to another hospital before full enteral feeds were achieved. Moreover, the following parameters were assessed in our study

a. Necrotizing enterocolitis (NEC) using Bell's criteria (stage $\geq 2 a)^{20}$ and focal intestinal perforation (FIP)

b. Bronchopulmonary dysplasia (BPD) according to Bancalari and Jobe. $^{21}$

c. Intraventricular hemorrhage (IVH) according to Papile et al..22

d. Retinopathy of prematurity (ROP) according to the International Committee for the Classification of Retinopathy of Prematurity. ${ }^{23}$

e. Intrauterine growth pattern (SGA) according Voigt et al... ${ }^{24}$

f. Catheter-related bloodstream infections (CRBSI) as defined by the National Healthcare Safety Network DoHQP. ${ }^{25}$

\section{Enteral nutrition policy}

A semi-standardized feeding protocol was applied in our NICU that defined feeding increments and handling of feeding difficulties. Breast milk feeding was encouraged, while donor human milk was not available. Bolus feedings were given at 2 or 3 hour intervals (usually 10 feeds/day). Our feeding policy was to start enteral feeds after passage of meconium with daily increases of $5-10-15 \mathrm{ml} / \mathrm{kg}$ of preterm formula (Alfare 14\%, Fa. Nestle $\AA$, Switzerland; Prematil $\AA$ and Prematil HA®, Milupa, Germany). If available, expressed breast milk was substituted for preterm formula as soon as possible. Breast milk was supplemented with a multicomponent fortifier (FM $85 \AA$, Nestle, Switzerland) at the discretion of the treating physician. Also, it is routine policy in our NICU to administer probiotics (1 caspsule of Infloran $\AA /$ day, most importanly to ELBW infants for a time period of at least 28 days). Full enteral feeds were defined as $150-160 \mathrm{ml} / \mathrm{kg} /$ day of milk feeds administered for more than one day. Exact nutritional intakes were determined daily by detailed chart review for the first 21 days of life, then weekly, until discharge.

Evacuation of meconium and gastrointestinal transit were promoted by regular rectal enemas and administration of gastrographin $(0.5-$ $1.0 \mathrm{ml} / \mathrm{kg}$ ) via a nasogastric tube. Daily modifications were possible according to the judgment of the treating physician. Prefeed gastric residuals of $1-2 \mathrm{ml}$ or $<30-35 \%$ of scheduled single-feed volume were tolerated in infants with unremarkable clinical examination of the abdomen. Feeding policies did not vary for specific subgroups of infants (e.g. ELBW vs. VLBW infants) and were identical in IUGR infants and no routine adjustments were made for these subgroups. In case of suspected NEC enteral feeds were withheld, a full diagnostic septic work-up (including full blood count, clinical chemistry, stool samples sent for microbiology testing, testing for occult blood, sonography of the abdomen, abdominal X-ray if indicated) was performed. If indicated, infants were started on antibiotics (Imipenem $60 \mathrm{mg} / \mathrm{kg} / \mathrm{d}$, TID) until full clinical recovery and CrP values $<10 \mathrm{mg} / \mathrm{l}$ at the discretion of the treating physician. ${ }^{26}$

Parenteral nutritionIn our cohort, parenteral nutrition was started immediately after birth. Total fluid volumes were initiated a $60-70 \mathrm{ml} /$ $\mathrm{kg} /$ day and then increased daily by $10-15 \mathrm{ml} / \mathrm{kg}$. Parenteral nutrition was tapered with increasing enteral supply and was discontinued when enteral feeds reached $140-160 \mathrm{ml} / \mathrm{kg} /$ day. Daily individual adjustments in parenteral protocol were made according to weight gain and infant's fluid status. Protein/amino acids were introduced at $1.0 \mathrm{~g} / \mathrm{kg} /$ day on day 1 , followed by increments of $0.5-1.0 \mathrm{~g} / \mathrm{kg} /$ day, aiming at a total protein supply of $3 \mathrm{~g} / \mathrm{kg} / \mathrm{day}$. Modifications were made according to serum urea and nitrogen concentrations. Parenteral lipid emulsions were started on day $1-2$ at $0.5 \mathrm{~g} / \mathrm{kg} /$ day and advanced by $0.5 \mathrm{~g} / \mathrm{kg} /$ day up to $1.5-2 \mathrm{~g} / \mathrm{kg} /$ day, and were supplemented with a multivitamin solution $(1 \mathrm{ml} / \mathrm{kg} /$ day $)$. Parenteral lipid supply was usually tapered when enteral feeds reached $100 \mathrm{ml} / \mathrm{kg} /$ day. Duration of intravenous access and duration of hospital stay were recorded as well.

\section{Anthropometric data}

Weight was measured daily or every other day depending on clinical stability and necessity; head circumference and body length were taken weekly from birth to discharge/transfer. For comparison of growth (weigth/length/head circumference), we used the percentiles for German infants (boys/girls) as published by Voigt and coworkers. $^{24}$

\section{Statistical analyses}

Relevant data were retrieved from an electronic hospital database (SAP, Germany) as well as from patient's hospital charts. Data are presented as medians, means, and ranges, standard deviation and standard error of the mean. For data interpretation we used frequencies and cross-tables. For further statistical analysis the Pearson Chi-Squre Test and Fischer's exact test were employed. Comparisons between groups were performed using the T-test for normally distributed variables, and the Wilcoxon/Kruskal-Wallis test for non-parametric variables. Statistical significance was assumed at $p \leq 0.05$. Statistical analyses were performed using SPSS, 20.0, Chicago, Illinois, USA. As our feeding regimen has been developed and put in place over an extended period of time in our unit, no statistical comparison with an own proper historical control group was possible. Instead, we compared our data with results available in published form in PubMed.

\section{Results}

In total, initially 120 infants were screened for study inclusion. Three infants were excluded because of gastrointestinal malformations (esophageal atresia (1), omphalocele (1), and gastroschisis (1)). One patient was excluded because of transfer to another hospital prior to achieving full enteral feeds. Thirteen patients were excluded because of death prior to achieving full feeds (respiratory failure (5), multiorgan failure (4), sepsis (2), IVH (1), pulmonary hemorrhage (1)). In these patients, death was unrelated to feeding practices and no signs suggestive of NEC (e.g. pneumatosis intestinalis) were noted clinically or on autopsy (e.g. necrotic bowel segments).

Mean birth weight of the 17 excluded infants was significantly lower $\left(\mathrm{p}^{* *}=0.008\right)$ than in the included study patients $(712 \pm 148 \mathrm{grams}$ (range: 480-980grams vs. $1121 \pm 266$ grams; range: 570-1490grams; $10-25$ th percentile). In the final study analysis, 74 singletons, 20 twin infants and 9 triplet infants were included (male 51/female 52) with a 
mean gestational age of 293 weeks (range: $254-341$ weeks). Antenatal steroids were given in 100/103 infants (one course (15); two courses (85). Twenty-two infants were growth restricted (10/103 symmetric IUGR; 12 asymmetrical IUGR). Median APGAR scores at 1, 5, and 10minutes were: 6 (1-9), 8 (4-10), and 9 (5-10). Mean umbilical arterial $\mathrm{pH}$ was $7.32 \pm 0.06$ (range: 6.99-7.41).

Feeds were initiated after a median period of 2 days (range: 1-7 days; mean: $2.2 \pm 1.0$ days). Full feeds were achieved after a median time span of 20 days (range: 10-48 days; mean: $20.4 \pm 6.1$ days) with a mean weight of $1313 \pm 311$ grams (range: $620-2000$ grams; $3-10$ th percentile). Neonates were discharged/transferred after $63.0 \pm 26.6$ days (range: $12-141$ days) with a mean weight of $2647 \pm 450$ grams ( $<3$ rd percentile; range 1030-3630 grams). Growth patterns (body weight/length and head circumference) according to sex are depicted in Table 1. Daily increments in enteral feeds for the first 21 days are shown in Figure 1. No significant differences were seen between IUGR and non-IUGR infants until achieving full feeds (19.3 vs. 20.7days; $\mathrm{p}=0.079)$, but birth weight was regained earlier ( 8.1 vs. 12.0

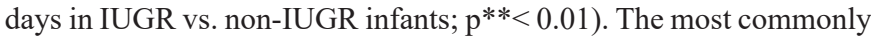
used formulas for starting feeds were Alfare 14\% (97), Prematil (3) and Prematil HA (3). Fifty-eight infants (56.3\%) received additional breast milk either during the initial phase of feeding or later in the course. During the clinical course, in 60 patients feeds could not be routinely increased at least on one occasion (range: 1-7 episodes); in 45 patients feeds had to be decreased (range: 1-9 episodes), and in 9 patients feeds had to be fully withheld at some stage (1-3 episodes; multiple entries possible).

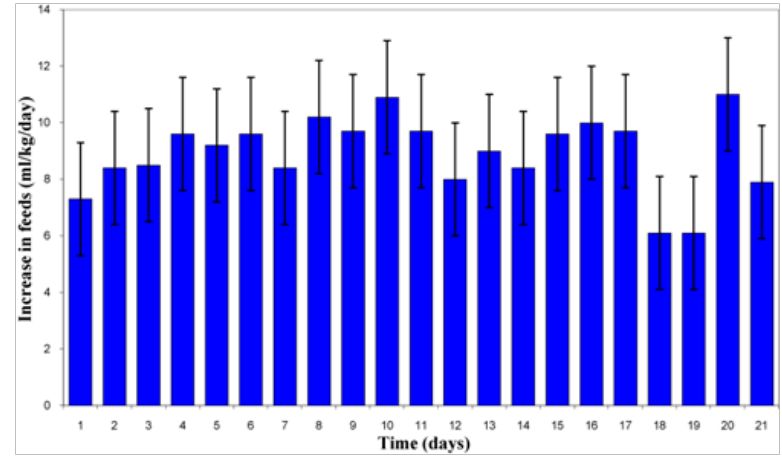

Figure I Increases in daily feeds $(\mathrm{ml} / \mathrm{kg})$ in study cohort during the first 21 days of enteral feeding ( $n=103$ infants given as (mean \pm SEM).

Rectal enemas (78/103) and oral gastrografin (70/103) were given mostly to infants weighing $<1000$ grams (multiple entries possible). Passage of meconium occurred after a median of 1 day (range: 1-3days; mean: $1.5 \pm 0.6$ days). Infloran ${ }^{\circledR}$ was given to $87 / 103$ infants, mostly infants weighing less than 1000grams.

With regard to complications and treatment modalities the following pattern was seen:

RDS: (96/103); Respiratory: No support (9), (nasal cannula oxygen (1), CPAP (28), conventional ventilation (29), HFOV (36); BPD: I=mild (16), II=moderate (6), III=severe (8); IVH: (33/103; grade III: 2; grade IV: 3); ROP: I (24), II (17), III (4), III+ (4), laser therapy (1).

Table I Growth (boys/girls): Body weight/length and head circumference at birth, when on full enteral feeds and when discharged

\begin{tabular}{|c|c|c|c|}
\hline Boys & At birth (29'weeks) & When on full enteral feeds ( $32^{\prime}$ weeks) & When discharged home $\left(39^{\circ}\right.$ weeks) \\
\hline $\begin{array}{l}\text { Body weight } \\
\text { (g) }\end{array}$ & $\begin{array}{l}\text { II } 20 \pm 264(600-1490) \\
\left(25^{\text {th }} \text { percentile }\right)\end{array}$ & $\begin{array}{l}1310 \pm 320(770-2000) \\
\left(3-10^{\text {th }} \text { percentile }\right)\end{array}$ & $\begin{array}{l}2628 \pm 47 \mid(I 030-3630) \\
\left(<3^{\text {th }} \text { percentile }\right)\end{array}$ \\
\hline $\begin{array}{l}\text { Body length } \\
(\mathrm{cm})\end{array}$ & $\begin{array}{l}37.4 \pm 3.1(31-43) \\
\left(25^{\text {th }} \text { percentile }\right)\end{array}$ & $\begin{array}{l}39.4 \pm 3.5(30.5-45) \\
\left(3-10^{\text {th }} \text { percentile }\right)\end{array}$ & $\begin{array}{l}46.3 \pm 3.0(34-54) \\
\left(<3^{\text {rd }} \text { percentile }\right)\end{array}$ \\
\hline $\begin{array}{l}\text { Head circumference } \\
\text { (cm) }\end{array}$ & $\begin{array}{l}26.3 \pm 2.2(21-30) \\
\left(25^{\text {th }} \text { percentile }\right)\end{array}$ & $\begin{array}{l}27.6 \pm 2.3(22-3 I .5) \\
\left(3-10^{\text {th }} \text { percentile }\right)\end{array}$ & $\begin{array}{l}33 . I \pm I .47(28.1-36) \\
\left(3-10^{\text {th }} \text { percentile }\right)\end{array}$ \\
\hline Girls & $\begin{array}{l}\text { At birth } \\
\left(29^{5} \text { weeks }\right)\end{array}$ & When on full enteral feeds ( $32^{4}$ weeks) & When discharged home $\left(39^{\circ}\right.$ weeks $)$ \\
\hline $\begin{array}{l}\text { Body weight } \\
\text { (g) }\end{array}$ & $\begin{array}{l}\text { II } 22 \pm 270(570-1490) \\
\left(10^{\text {th }}-25^{\text {th }} \text { percentile }\right)\end{array}$ & $\begin{array}{l}1316 \pm 305(620-1940) \\
\left(3-10^{\text {th }} \text { percentile }\right)\end{array}$ & $\begin{array}{l}2665 \pm 432(1480-3630) \\
\left(3^{\text {rd }} \text { percentile }\right)\end{array}$ \\
\hline $\begin{array}{l}\text { Body length } \\
(\mathrm{cm})\end{array}$ & $\begin{array}{l}37.6 \pm 3.1(31-42) \\
\left(25^{\text {th }}-50^{\text {th }} \text { percentile }\right)\end{array}$ & $\begin{array}{l}39.4 \pm 3.1(31-45) \\
\left(10^{\text {th }} \text { percentile }\right)\end{array}$ & $\begin{array}{l}46.6 \pm 2.3(39-5 I) \\
\left(<3^{\text {rd }} \text { percentile }\right)\end{array}$ \\
\hline $\begin{array}{l}\text { Head circumference } \\
(\mathrm{cm})\end{array}$ & $\begin{array}{l}26.1 \pm 2.1(2 I .5-30) \\
\left(25^{\text {th }} \text { percentile }\right)\end{array}$ & $\begin{array}{l}27.8 \pm 22.5-31) \\
\left(3-10^{\text {th }} \text { percentile }\right)\end{array}$ & $\begin{array}{l}33.0 \pm 1.3(29.6-36) \\
\left(3-10^{\text {th }} \text { percentile }\right)\end{array}$ \\
\hline
\end{tabular}

The incidence of NEC (Bells stage $\geq 2 a$ ) was $0 / 103(0 \%)$. In 2/103 infants NEC was suspected on clinical grounds, but could not be confirmed by laboratory studies; in 4 neonates abdominal distension and heme-positive stools occurred temporarily without further clinical or laboratory evidence suggestive of NEC. In these infants 4 feeds were temporarily withheld (3) or reduced (1), but no antibiotic treatment or surgical intervention was required. No case of FIP was seen in our cohort. In 5/103 neonates, CRBSI (coagulase-negative Staph. (5); 2.4 infections/1000 device days) were seen. Moreover, 4 proven septic episodes were seen (Acinetobacter (1), Pseudomonas aeruginosa (1), Staph. aureus (1), and Staph. epidermidis (1)); 3 neonates developed only clinical signs of systemic inflammation without bacterial proof. All 103 infants survived and were discharged/transferred after $63 \pm 26.6$ days (range: $12-141$ days) with a mean weight of $2647 \pm 450$ grams.

\section{Discussion}

Using a very conservative enteral feeding regimen in our study cohort with daily feed increments of $5-10-15 \mathrm{ml} / \mathrm{kg}$, we could demonstrate a dramatically low incidence of NEC over a 2-year study period $(0 / 103 ; 0 \%)$. This is in frank contrast to results from large data sets demonstrating an incidence of NEC in this cohort of approximately $4-7 \% .^{2-5}$. Although we cannot rule other confounding variables (e.g. high rate of antenatal steroids, routine use of probiotics, rectal enema, use of gastrographin, etc.), our data suggest an association between a very conservative feeding regimen and an exceptionally low incidence of NEC. Of note, while using small increases in daily feeds, we did initiate enteral feeds quite early with a median time interval of 2 days following birth when compared to previous reports ${ }^{10}$ of importance, IUGR infants are considered to have a higher risk of developing NEC, 
especially if there has been antenatal detection of absent or reversed end-diastolic flow velocities (AREDFV) of the fetal aorta or umbilical artery. ${ }^{8}$ However, the association of AREDFV with NEC could not be consistently demonstrated in another study. ${ }^{27}$ Paradoxically and of importance, most trials of enteral feeding regimens have specifically excluded infants with evidence of IUGR from participating because of the perceived high risk of developing NEC. Of note, in our study analysis we could not demonstrate any relevant differences between SGA $(n=22)$ and non-SGA $(n=81)$ infants with regard to enteral feeding practices, feeding intolerance, and the occurrence of NEC. Of note, ex utero growth patterns in our study cohort was abnormal when compared to reference in utero growth with a drop in body weight, body length and less pronounced in head circumference. ${ }^{24}$. Although the existing intrauterine growth charts are used to evaluate and manage postnatal growth, limitations and long-term outcome of this procedure are still a controversial issue. For example, catch up growth seems to have a positive contribution to neurological development but a negative to cardiovascular risk..$^{28}$

However, it is noteworthy to mention that the decrease in growth velocity was comparable - possibly even less pronounced-when compared to data from other studies. ${ }^{24}$ Ehrenkranz and co-workers demonstrated that at hospital discharge most infants born with a gestational age of 24-29 weeks did not achieve the median birth weight of the reference group at the same postmenstrual age. In this study, gestational age, race, and gender had no effect on growth within $100 \mathrm{~g}$ birth weight strata. ${ }^{29}$ When discussing key issues like enteral nutritional regimens and the rate of feeding advancement in this very vulnerable patient cohort, it is important to realize what longterm implications severe NEC will have on these individuals - most importantly a disproportionate increase in poor neurological outcome including cerebral palsy. ${ }^{17}$ Although slow feeding advancement has been linked to prolonged parenteral nutrition, gut atrophy, nosocomial infection, and delayed hospital discharge, in our opinion the detrimental consequences of NEC with reported mortality rates of $15 \%-30 \%{ }^{1-4}$ outweigh these potential risks. Of note, no excess in the number of CRBSI (2.4 infections/1000 device days) was seen in our study population when compared to data reported in previous reports (3.3 infections $/ 1000$ device days). ${ }^{30}$ The overall infection in our cohort rate was lower when compared to data of other reports assessing slow feeding regimens. ${ }^{31}$

Some limitations and possible confounders do apply to our study analysis. First, this was a retrospective cohort study with all inherent shortcomings to this study concept. Of note, since our feeding policy has been developed and put in place for many years in our NICU, it was unfeasible to use an own, proper historical control group since many other changes in neonatal intensive care have been realized in parallel. Thus, we can only compare our results to published data in the literature. Second, in our hospital, highly-hydrolysated infant formula (Alfare 14\%) was given initially to a large proportion of infants $(97 / 103)$ in combination with breast milk $(58 / 103)$ as opposed to many other institutions that use other infant formulas. Of note, highly-hydrolyzed formula has been shown to improve feeding tolerance and shorten the time span until achieving full feeds in VLBW infants. ${ }^{32}$. This may have possibly had a positive effect on tolerating enteral feeds. Third, we routinely administered probiotics in our patients, which may not be done in other NICUs. Recent analyses have demonstrated a benefit of probiotics with regard to the incidence of NEC in preterm infants. ${ }^{6,7}$ However, even in the period prior to supplementing probiotics in our unit, the incidence of NEC was well below the reported rates in other studies. ${ }^{1-4}$. Fourth, early administration of rectal enemas and oral gastrographin $(0.5-1.0 \mathrm{ml} /$ $\mathrm{kg}$ ) with subsequent early passage of meconium-when compared to normal passage $\mathrm{e}^{33}$ may have had a positive effect on building up enteral feeds without occurrence of NEC. This is in line with other reports that have demonstrated that rapid meconium evacuation appears to be a key factor for the feeding tolerance of ELBW infants during the first 14 days of life. ${ }^{34}$ However, while having a beneficial effect on the time to full enteral feedings, the use of high-dose oral contrast agent in VLBW infants was associated with an excessive rate of NEC (21\%) in a recent report. ${ }^{35}$. Moreover, it is important to note that-while the incidence of NEC was disproportionately low in in our cohort, other mobidities (BPD, ROP, IVH) and the overall mortality rate (13/120) were not lower when compared to data from other European countries and centers. ${ }^{5,36}$

However, although we only studied a cohort over two years, data from the previous 10 years in our NICU have rendered comparable results with an annual NEC incidence (stage $\geq$ IIa) of less than $1 \%$ including FIP. ${ }^{37}$. Moreover, we included infants with a great variety of medical problems (including severe IVH with clinical signs of raised intracranial pressure), which most likely will have affected the process of building up enteral feeds. Also, the definition of full enteral feeds of $150-160 \mathrm{ml} / \mathrm{kg} / \mathrm{d}$ was rather high and conservative when compared to other definitions (120-140 ml/kg/d), thus also prolonging the time interval until achieving full enteral feeds in our study.

\section{Conclusion}

Because of the fulminant nature of NEC, it is unlikely that new treatment strategies will provide major breakthroughs in reducing its associated mortality and morbidity in the near future. Therefore, it is important to prevent this catastrophic event, and effective preventive strategies are likely to yield better results. Given our study results, we suggest that future RCTs will compare a very conservative enteral feeding regimen (daily increase of $5-10-15 \mathrm{ml} / \mathrm{kg} /$ day) to a more aggressive one $(25-30 \mathrm{ml} / \mathrm{kg} /$ day $)$ as recently promoted by A.S.P.E.N. ${ }^{18}$ Of note, a large multi-center RCT comparing different enteral feeding regimens is currently conducted in VLBW infants. ${ }^{38} \mathrm{It}$ will be of paramout importance to include both short- and long-term outcome variables in order to adequately assess potential differences between these two approaches.

Possibly, the overall positive outcome with regard to the occurrence of NEC in our study population was not only attributed to low daily increases in enteral feeds, but rather to the overall feeding policy in our unit. Therefore, we would alternatively suggest that future studies in this field of neonatology should assess a "compound/composite" interventional approach. These studies should combine two or more interventions that have proved to be at least partially beneficial (positive trend) and assess prospectively whether the combination of these interventions will reduce the incidence of NEC. ${ }^{39}$

Moreover, it will be important to take into consideration geographic, political and economic aspects. In low and middle income countries, enteral feeding concepts may very well vary quite substantially from those applied in highly-industrialized Western countries given the differences between these countries. ${ }^{40}$ Data from the German Neonatal Network (GNN) in the year 2010 demonstrated that in addition to respiratory pathology the majority of non-survivors $(221 / 2.221)$ suffered from potentially preventable diseases (inflammatory diseases including sepsis or NEC). ${ }^{5}$ In order to decrease the rate of these preventable complications of preterm birth, future trials should focus on prophylaxis and therapy optimization strategies for these outcomes. 


\section{Acknowledgments}

None.

\section{Conflicts of interest}

The authors have no conflict of interests related to this publication and have not received any grants.

\section{Funding}

None.

\section{References}

1. Neu J, Walker WA. Necrotizing enterocolitis. $N$ Engl $J$ Med. 2011;364(3):255-264.

2. Horbar JD, Carpenter JH, Badger GJ, , et al. Mortality and neonatal morbidity among infants 501 to 1500 grams from 2000 to 2009 . Pediatrics. 2012;129(6):1019-1026.

3. Sankaran K, Puckett B, Lee DS, et al. Variations in incidence of necrotizing enterocolitis in Canadian neonatal intensive care units. $J$ Pediatr Gastroenterol Nutr. 2004;39(4):366-372.

4. Fitzgibbons SC, Ching Y, Yu D, et al. Mortality of necrotizing enterocolitis expressed by birth weight categories. J Pediatr Surg. 2009;44(6):1072-1075.

5. Stichtenoth G, Demmert M, Bohnhorst B, S et al. Major contributors to hospital mortality in very-low-birth-weight infants:data of the birth year 2010 cohort of the German Neonatal Network. Klin Padiatr. 2012;224(4):276-281.

6. Alfaleh K, Anabrees J, Bassler D, et al. Probiotics for prevention of necrotizing enterocolitis in preterm infants. Cochrane Database Syst Rev. 2011;16(3):CD005496

7. Deshpande G, Rao S, Patole S, et al. Updated meta-analysis of probiotics for preventing necrotizing enterocolitis in preterm neonates. Pediatrics. 2010;125(5):921-930.

8. Chauhan M, Henderson G, McGuire W. Enteral feeding for very low birth weight infants:reducing the risk of necrotising enterocolitis. Arch Dis Child Fetal Neonatal Ed. 2008;93(2):F162-F166.

9. Berseth CL, Bisquera JA, Paje VU (2003) Prolonging small feeding volumes early in life decreases the incidence of necrotizing enterocolitis in very low birth weight infants. Pediatrics. 2003;111(3):529-534.

10. Morgan J, Young L, McGuire W. Delayed introduction of progressive enteral feeds to prevent necrotising enterocolitis in very low birth weight infants. Cochrane Database Syst Rev. 2011;16(3):CD001970.

11. Morgan J, Young L, McGuire W. Slow advancement of enteral feed volumes to prevent necrotising enterocolitis in very low birth weight infants. Cochrane Database Syst Rev. 2011;16(3):CD001241.

12. Henderson G, Anthony MY, McGuire W. Formula milk versus maternal breast milk for feeding preterm or low birth weight infants. Cochrane Database Syst Rev. 2007;17(4):CD002972.

13. Kennedy KA, Tyson JE, Chamnanvanikij S. Early versus delayed initiation of progressive enteral feedings for parenterally fed low birth weight or preterm infants. Cochrane Database Syst Rev. 2000;2:CD001970.

14. Fallon EM, Nehra D, Potemkin AK, et al. A.S.P.E.N. clinical guidelines:nutrition support of neonatal patients at risk for necrotizing enterocolitis. JPEN J Parenter Enteral Nutr. 2012;36(5):506-523

15. Hans DM, Pylipow M, Long JD, Tet al. Nutritional practices in the neonatal intensive care unit:Analysis of a 2006 neonatal nutrition survey. Pediatrics. 2009;123(1):51-57.
16. Klingenberg C, Embleton ND, Jacobs SE, et al. Enteral feeding practices in very preterm infants:an international survey. Arch Dis Child Fetal Neonatal Ed. 2012;97(1):F56-F61.

17. Rees CM, Pierro A, Eaton S. Neurodevelopmental outcomes of neonates with medically and surgically treated necrotizing enterocolitis. Arch Dis Child Fetal Neonatal Ed. 2007;92:F193-F198.

18. Vasu V, Modi N. Assessing the impact of preterm nutrition. Early Hum Dev. 2007;83(12):813-818.

19. Berseth CL, Bisquera JA, Pajc VU. Prolonging small feeding volumes early in life decreases the incidence of necrotizing enterocolitis in very low birth weight infants. Pediatrics. 2003;111(3):529-534.

20. Bell MJ, Ternberg JL, Feigin RD, et al. Neonatal necrotizing enterocolitis:therapeutic decisions based upon clinical staging. Ann Surg. 1978;187:1-7.

21. Jobe AH, Bancalari E. Bronchopulmonary dysplasia. Am J Respir Crit Care Med. 2001;163(7):1723-1729.

22. Papile LA, Burstein J, Burstein R, et al. Incidence and evolution of subependymal and intraventricular hemorrhage:a study of infants with birth weights less than 1,500 gm. J Pediatr. 1978;92(4):529-534.

23. International Committee for the Classification of Retinopathy of Prematurity. The International Classification of Retinopathy of Prematurity revisited. Arch Ophthalmol. 2005;123(7):991-999

24. Voigt M, Rochow N, Hesse V, et al. Short communication about percentile values of body measures of newborn babies. Z Geburtshilfe Neonatol. 2010;214(1):242-249

25. National Healthcare Safety Network DoHQP (30). Centers for Disease Control and Prevention:CDC/NHSN surveillance definition of health care-associated infection and criteria for specific types of infections in the acute care setting. 2013.

26. Mathers NJ, Pohlandt F. Diagnostic audit of C-reactive protein in neonatal infection. Eur J Pediatr. 1987;146(2):147-151.

27. Dorling J, Kempley S, Leaf A. Feeding growth restricted preterm infants with abnormal antenatal Doppler results. Arch Dis Child Fetal Neonatal Ed. 2005;90(5):F359-F363.

28. Sauer PJ. Can extrauterine growth approximate intrauterine growth? Should it? Am J Clin Nutr. 2007;85(2):608S-613S.

29. Ehrenkranz RA, Younes N, Lemons JA, et al. Longitudinal growth of hospitalized very low birth weight infants. Pediatrics. 1999;104(2 Pt 1):280-289

30. Geffers C, Gastmeier A, Schwab F, et al. Use of central venous catheter and peripheral venous catheter as risk factors for nosocomial bloodstream infection in very-low-birth-weight infants. Infect Control Hosp Epidemiol. 2010;31(4):395-401.

31. Hartel C, Haase B, Browning-Carmo K, et al. Does the enteral feeding advancement affect short-term outcomes in very low birth weight infants? J Pediatr Gastroenterol Nutr. 2009;48(4):464-470.

32. Mihatsch WA, Franz AR, Hogel J, et al. Hydrolyzed protein accelerates feeding advancement in very low birth weight infants. Pediatrics. 2002;110(6):1199-1203.

33. Bekkali N, Hamers SL, Schipperus MR, et al. Duration of meconium passage in preterm and term infants. Arch Dis Child Fetal Neonatal Ed. 2008;93(5):F376-F379.

34. Mihatsch WA, Franz AR, Lindner W, et al. Meconium passage in extremely low birthweight infants and its relation to very early enteral nutrition. Acta Paediatr. 2011;90(4):409-411.

35. Haiden N, Norooz F, Klebermass-Schrehof K, et al. The effect of an osmotic contrast agent on complete meconium evacuation in preterm infants. Pediatrics. 2012;130(6):e1600-e1606. 
36. Zeitlin J, Draper ES, Kollee L, et al. Differences in rates and short-term outcome of live births before 32 weeks of gestation in Europe in 2003:results from the MOSAIC cohort. Pediatrics. 2008;121(4):e936-e944.

37. Meyer S, Gortner L. Necrotizing enterocolitis in preterm infants. JPEN J Parenter Enteral Nutr. 2013;37(1):13.

38. SIFT Investigators Group. Early enteral feeding strategies for very preterm infants:current evidence from Cochrane reviews. Arch Dis Child Fetal Neonatal Ed. 2013;98(6):F470-F472.
39. Meyer S, Gottschling S, Gortner L. Evidence-based medicine in neonatology:time to re-think. Eur J Pediatr. 2008;167(9):1089.

40. Meyer S, Butte M, Gortner L, et al. Research in neonatology:a global perspective. Acta Paediatr. 2013;102(8):e346. 